\title{
Single incision laparoscopic cystectomy for a huge fimbrial cyst: a rare case report
}

\author{
Ramesh Bettaiah, Chandana A Reddy*, Pooja Gupta
}

Tertiary and referral centre for Gynecologic Laparoscopy, Dr Ramesh Hospital, Bangalore, Karnataka, India

Received: 03 August 2015

Revised: 25 August 2015

Accepted: 29 August 2015

\author{
*Correspondence: \\ Dr. Chandana Reddy, \\ E-mail: drchandana.a@gmail.com
}

Copyright: $(\odot$ the author(s), publisher and licensee Medip Academy. This is an open-access article distributed under the terms of the Creative Commons Attribution Non-Commercial License, which permits unrestricted non-commercial use, distribution, and reproduction in any medium, provided the original work is properly cited.

\begin{abstract}
A case of huge fimbrial cyst is presented, occurring in a 26 year old female. She presented in outpatient department with an incidental diagnosis of a huge cystic mass diagnosed during her routine medical check-up. She was asymptomatic. Ultrasound and CT scan showed an abdominopelvic cystic mass in left adnexa and a right dermoid cyst. Single incision laparoscopic surgery was performed and a huge right fimbrial cyst of $35 \mathrm{~cm}$ was noted along with left dermoid cyst. We did bilateral cystectomy through single port laparoscopy. Although there are a few case reports on huge fimbrial cysts which were managed traditionally by laparotomy and recently multiport laparoscopic surgeries, the technique of single incision laparoscopic surgery for proved benign cysts has been described here.
\end{abstract}

Keywords: Fimbrial cyst, Dermoid cyst, Abdominopelvic cystic mass

\section{INTRODUCTION}

Fimbrial cyst represent approximately $10 \%$ of adnexal masses. ${ }^{1}$ Fimbrial cysts usually arise in broad ligament and are thin walled and unilocular. It is very difficult to differentiate a fimbrial cyst from ovarian cyst on ultrasound imaging and thereby confirming only intra operatively. In most cases they are very small, but very few cases are reported in the literature where they exceed $15 \mathrm{~cm}$ of diameter. When large they may present with pain, torsion or rupture, thereby requiring surgery.

Management includes traditional way of cystectomy by laparotomy, recently multiport laparoscopic surgery. We present a simple technique of Single Port Laparoscopic Surgery for the management of a huge benign fimbrial cyst of $35 \mathrm{~cm}$.

\section{CASE REPORT}

A 26 year old unmarried girl presented at our outpatient department with an incidental ultrasound diagnosis of a large intraperitoneal cystic lesion during a routine medical check-up. She was asymptomatic. On abdominal examination, a cystic tense mass was felt up to the epigastrium.

CT scan showed a large abdominopelvic cyst of size $33 \mathrm{x}$ $13 \times 24 \mathrm{~cm}$. Right ovary was seen separate from the cyst. Left ovary had a dermoid cyst measuring $3 \times 2.5 \mathrm{~cm}$. Both kidneys were normal, with no evidence of hydronephrosis, both ureters were normal.

We proceeded with single incision Laparoscopic surgery. The technique involved insertion of a veress needle with a suction tubing attached to it through the umbilicus and into the cyst. Clear fluid of $7500 \mathrm{ml}$ was drained. Once the cyst collapsed, a $2 \mathrm{~cm}$ umbilical incision was given, layers of abdomen opened up to the peritoneum. SILSCovidien port was introduced through the umbilicus. Per operatively uterus was normal in size and contour. Right ovary was normal. Right fimbria had a collapsed cyst of $35 \times 25 \mathrm{~cm}$ size. Cystectomy was done in the routine method. Left tube was normal. Left ovary had a dermoid cyst of $4 \times 3 \mathrm{~cm}$ and a dermoid cystectomy was done. Dermoid cyst was placed in endobag and retrieved 
through umbilical port. Fimbrial cyst wall was retrieved through umbilical port and sent for HPE (Figure 1).

On Histopathology the fimbrial cyst wall was lined by a flat cuboidal epithelium suggestive of simple cyst, the left ovarian cyst was found to be mature cystic teratoma. On follow up patient had a scarless abdomen, as the umbilical scar was not apparent. Postoperative recovery was rapid with minimal requirement for analgesics.

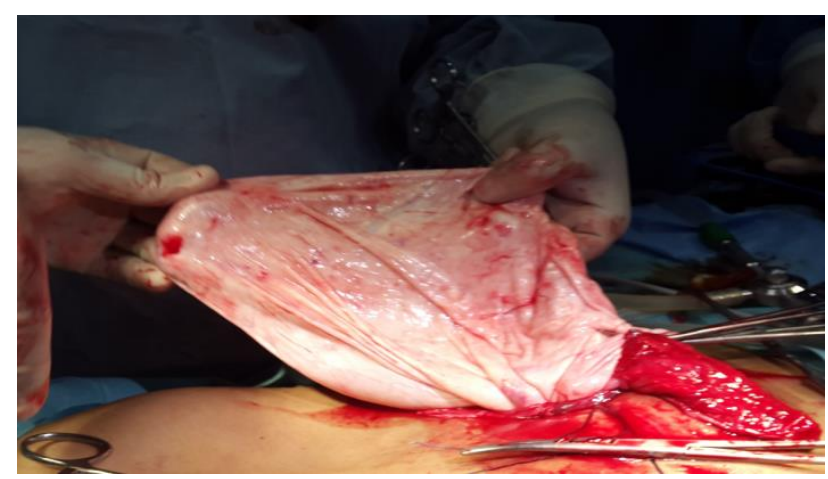

Figure 1: Paraovarian cyst removed through the umbilicus following SILS cystectomy.

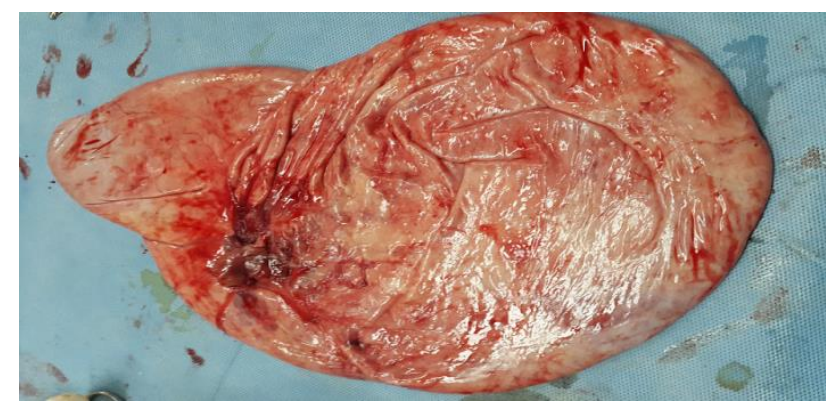

Figure 2: Paraovarian cyst $(35 \mathrm{~cm})$ after complete removal through SILS cystectomy.

\section{DISCUSSION}

Small fimbrial cysts are most commonly seen in the reproductive age group and are often indistinguishable from simple ovarian cysts. They are mostly asymptomatic.

Fimbrial cysts can sometimes become larger and present with symptoms due to adjacent organ compression. They can present with pelvic tenderness, usually unilateral, abnormal uterine bleeding, and dyspareunia. In our case though the fimbrial cyst was so huge, she was asymptomatic and was detected as an incidental finding.

Fimbrial cysts of such huge size as in our case are a rare finding. There is no literature of removal of such huge fimbrial cyst through this technique of single port laparoscopic surgery. Few reports have been published reporting SILS in benign ovarian cystectomy. ${ }^{2,3}$

We have used a simple technique of cyst aspiration before proceeding with laparoscopic surgery. This technique overcomes the disadvantage of not having the required space in the abdominal cavity for trocar insertion and further surgical procedure. Since the cyst collapses after aspiration, a good space is obtained in the abdominal cavity to proceed with the surgical procedure. This method can be either followed by multiple port laparoscopy or SILS depending on the expertise of the surgeon. SILS has an advantage of less pain, faster recovery and improved cosmetic results. The single port approach to surgery requires only one entry point, typically in the umbilical region. So, single incision laparoscopy may be considered a less invasive approach with reduced port site complications like hernia, vascular and soft tissue injuries. In cases of such huge clear cysts, SILS can be considered after aspiration of fluid, as most fimbrial clear cysts are mostly benign.

There are few contraindications to SILS cystectomy. Most important would be a malignant ovarian cyst. Hence in any suspicion of malignancy, this technique should not be done.

Using the described technique, we conclude that SILS is feasible and safe and should be adopted in treatment of large benign ovarian cysts.

Funding: No funding sources

Conflict of interest: None declared

Ethical approval: Not required

\section{REFERENCES}

1. Leanza V, Coco L, Genovese F, Et Al. Laparoscopic Removal of A Giant Paratubal Cyst Complicated By Hydronephrosis. Il Giornale Di Chirurgia. 2013;34(11-12):323-5.

2. Fagotti A, Fanfani F, Rossitto C, Marocco F, Gallotta V, Romano F, Et Al. Laparoendoscopic Single-Site Surgery For The Treatment Of Benign Adnexal Disease: A Prospective Trial. Diagn Ther Endosc. 2010;2010:108258.

3. Escobar Pf, Bedaiwy Ma, Fader An, Falcone T. Laparoendoscopic Single-Site (Less) Surgery in Patients with Benign Adnexal Disease. Fertil Steril. 2010;93(2074):E7-10.

4. Garg P, Misra S, Thakur JD, Song J. Single incision laparoscopic surgery ovarian cystectomy in large benign ovarian cysts using conventional instruments. Journal of Minimal Access Surgery. 2011;7(4):2325.

Cite this article as: Bettaiah R, Reddy CA, Gupta P. Single incision laparoscopic cystectomy for a huge fimbrial cyst: a rare case report. Int J Reprod Contracept Obstet Gynecol 2015;4:1637-8. 